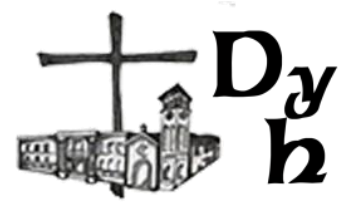

No estoy yo solo

Valentín García Lazzarini

Dios y el hombre, vol. 4, n. 2, e070, 2020

ISSN 2618-2858 - https://doi.org/10.24215/26182858e070

https://revistas.unlp.edu.ar/DyH/index Cátedra libre de pensamiento cristiano - UNLP

Seminario Mayor San José La Plata, Buenos Aires, Argentina

\title{
NO ESTOY YO SOLO
}

\author{
I'm not alone
}

Valentín García Lazzarini

garcialazzarinivalentin@gmail.com

Seminario Mayor San José - La Plata - Argentina

\section{Resumen}

El autor ofrece un relato de vivaz lectura apelando a un relato Jorge Luis Borges.

\section{Abstract}

Author develops a fascinating story invoking a Borges's tale. 
Más que un cuento, me resultó una viva declaración de algo que alguna vez había experimentado Borges y que ya olvidó; lo cual me invita a pensar que, aunque loco, el asunto podría estar mucho más allá de lo que imaginariamente viví en el relato, condicionado al testimonio evidentemente recortado de una realidad de la que nunca había sido parte.

Descarté finalmente, entre satisfecho e intrigado, aquel texto de mi escritorio y me dirigí con la taza sucia hacia la cocina, ansioso en compartir con Mariel mi interpretación de "El Aleph". Terminó, como era de esperar, en una metódica reacción por parte de mi mujer, en la que, en conclusión, no era más que un viejo profesor de filosofía loco que cree en historias inventadas por algún loco peor. Quizás esté medio rayado, pero elijo abrirme a la probable existencia de aquello que termina por ser tan increíble como en su momento lo fue la teoría de la esfericidad de la tierra. ¡Pues más rayado estará Hernando de Magallanes entonces!

Esa misma noche, luego de las exquisitas gambas al ajillo de Mariel, me pidió que le hiciese un favor. Ella se había empecinado con una aplicación de venta y compra online, algo así como un trueque cibernético. Mi tarea consistía en confeccionar una lista con mis chatarras antiguas a las que ya no les proporcionaba uso para ponerlas en venta, y recaudar algún dinero. Entonces, me dirigí al altillo y comencé a enumerarlas.

¡Cuántos recuerdos llegaron hacia mí esa noche! Allí estaba mi primera Stratocaster albirroja que me compró mi Padre; la empolvada novena a San Pio de Pietrelcina que me regalaron el día de mi comunión; mis apuntes universitarios de la facultad de filosofía; aquella boina azul escocesa con la que nunca armonicé; mi antiguo comic de Marvel, sobre el primer encuentro de Spiderman con el Capitán América; las vajillas del matrimonio de mis padres; y aquel espejo ovalado de marco grueso, proveniente de mi tío abuelo Julio, el cual lo heredó de su bisabuelo alemán Johan (nombre de origen hebreo que significa regalo de Dios), que tan poderosamente llamó mi atención. Estaba al final de la habitación detrás de unas cajas, junto a un reloj de nácar que marcaba las 22:43. Se divisaba tan solo la curva superior izquierda del espejo, dado que el resto estaba cubierto por una sábana grande que en algún momento debió de ser blanca. Intrigado y atraído por ver mi reflejo en aquella antigüedad, quité la sábana. Mi retrato se manifestaba borroso y hasta movedizo. Al cabo de un minuto, marcado por el reloj de nácar, comencé a 
experimentar cierta anomalía. La piel de gallina fue tan sólo el comienzo de una serie de síntomas emergentes de la situación. No sabía lo que sucedía, pero de alguna manera una sobrenaturalidad se apoderó de mí y de toda la sensatez del lugar. Borges vio el Aleph, yo entré en él...

\author{
Tras el temblor opaco de las lágrimas, \\ no estoy yo solo. \\ Tras el profundo velo de mi sangre, \\ no estoy yo solo. \\ Tras la primera música del día, \\ no estoy yo solo. \\ Tras la postrera luz de las montañas, \\ no estoy yo solo. \\ Tras el estéril gozo de las horas, \\ no estoy yo solo. \\ Tras el augurio helado del espejo, \\ no estoy yo solo. \\ No estoy yo solo; me acompaña, en vela [...] \\ ...la pura eternidad de quien existe ${ }^{1}$.
}

Era igual que aquí, pero allí y en todos lados. Mis capacidades no se limitaban a observar, yo podía estar y hacer. Pasé a existir en todos los puntos universales simultáneamente. Donde nadie sabe de mí y yo soy parte de todo, diría Gustavo. Estuve en la bala que se dispara y el cuerpo que muere; estuve en el lápiz que dibuja y la goma que borra; estuve en la marea que sube y la arena que se moja. Estuve antes y estoy después. Estoy detrás de ti, pero ya me fui. Pude ayudar y pude empeorar, pero nunca pude comprender.

Pues no era yo quien debía estar, ni yo quien debía hacer. Mis objetivos no eran claros, incluso carecía de un plan. Finalmente pude comprender, que la soberbia, cual Adán y Eva, me había consumido y que mi lugar original era el indicado.

\footnotetext{
${ }^{1}$ Himno vespertino litúrgico.
} 


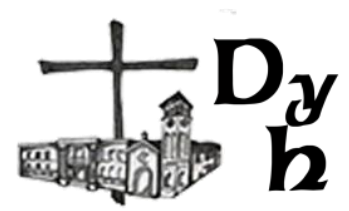

Miré el reloj de nácar, y el tiempo no había avanzado. Abrí mi vieja caja de herramientas y tomé el martillo. No me arrepiento de haberlo destruido. Bajé las escaleras y entregué la lista a Mariel. 